\title{
O ensino de Geografia na perspectiva da Educação Inclusiva
}

\section{The Geography Teaching from the perspective of Inclusive Education}

\section{La Enseñanza de la Geografía desde la perspectiva de la Educación Inclusiva}

\author{
Vilomar Sandes Sampaio ${ }^{1}$ https://orcid.org/0000-0003-2897-2197 \\ Andrecksa Viana Oliveira Sampaio ${ }^{2}$ https://orcid.org/0000-0002-7826-0908 \\ Edinaldo Sousa Almeida ${ }^{3}$ https://orcid.org/0000-0003-1416-2935
}

\footnotetext{
${ }^{1}$ Pós-doutor em Geografia pela Universidade Federal de Sergipe (UFS). Professor Adjunto do Departamento de Geografia da Universidade Estadual do Sudoeste da Bahia (UESB). Professor Permanente do Prógrama de Pós-Graduação em Geografia- PPGEO-UESB- Vitória da Conquista-Bahia-Brasil, vilomar@uesb.edu.br

${ }^{2}$ Pós- Doutora em Geografia pela Universidade Federal de Sergipe (UFS). Professor Adjunto do Departamento de Geografia da Universidade Estadual do Sudoeste da Bahia (UESB). Vitória da Conquista-Bahia-Brasil andrecksa.oliveira@uesb.edu.br

${ }^{3}$ Especialista em Geograifa pela Universidade Estadual do Sudoeste da Bahia (UESB). Vitória da Conquista-Bahia-Brasil, edinaldogeo09@gmail.com
}

Recebido em: 20/07/2019

Aceito para publicação em: 30/09/2020

\section{Resumo}

O artigo tem como objetivo discutir o ensino de Geografia na Educação Inclusiva, bem como, a formação docente e o processo de ensino e aprendizagem nesta modalidade de ensino. Para isso foi necessária uma revisão teórica sobre a temática. A educação de caráter inclusivo passa a ter uma maior importância a partir da década de 1980, com a Constituição Federal de 1988 e a Lei de Diretrizes e Bases da Educação Nacional de 1996, que consolidaram o ensino inclusivo na rede regular de ensino. Os desafios são muitos, porém o processo de inclusão não se estabelece apenas na prática em sala de aula, mas sim, nas diversas relações desenvolvidas cotidianamente.

Palavras-chave: Ensino de Geografia. Educação Inclusiva. Formação docente.

\begin{abstract}
This article aims to discuss Geography Teaching in Inclusive Education, as well as teacher training and the process of teaching and learning in this modality of schooling. This required a theoretical review of the subject. Inclusive education has become more important since the 1980s, with the
\end{abstract}

Geopauta, Vitória da Conquista, ISSN: 2594-5033, V. 4, n.3, 2020, p.(210-226) http://periodicos2.uesb.br/index.php/geo, 
Federal Constitution of 1988 and the Law of Guidelines and Bases to National Education of 1996, which consolidated inclusive education in the regular school system. The challenges are many, but the inclusion process is not only established in classroom practice, but in the various relationships developed on a daily basis.

Keywords: Geography Teaching. Inclusive education. Teacher training.

\section{Resumen}

Este artículo tiene como objetivo discutir la Enseñanza de la Geografía en la Educación Inclusiva, así como la capacitación docente y el proceso de enseñanza y aprendizaje en esta modalidad de enseñanza. Esto requirió una revisión teórica del tema. La educación inclusiva se ha vuelto más importante desde la década de 1980, con la Constitución Federal de 1988 y la Ley de Directrices y Bases de la Educación Nacional de 1996, que consolidó la educación inclusiva en el sistema escolar regular. Los desafíos son muchos, pero el proceso de inclusión no solo se establece en la práctica en el aula, sino en las diversas relaciones que se desarrollan diariamente.

Palabras clave: Enseñanza de geografia. Educación inclusiva. Formación del profesorado.

\section{Introdução}

Um dos principais desafios para a educação inclusiva diz respeito a formação e a prática docente, que muitas vezes não condizem com a demanda e a necessidade desta modalidade de ensino. Isso se deve a diversos fatores, desde as condições de trabalho, como estrutura física das instituições, as carências do processo formativo e até a falta de capacitação continuada para atuar com esse público, pois:

[...] a escola nem sempre proporcionará ao professor as condições adequadas ou ideais de trabalho, estejam estas voltadas para a questão da gestão ou da infraestrutura e dos recursos educacionais. O professor, no entanto, não deve esperar que isso aconteça para que dentro de suas possibilidades cumprir com a sua função social (ALMEIDA; et. al, 2013, p. 110)

Porém, apesar dos diversos desafios que são normalmente encontrados, é importante destacar que trabalhar com Educação Inclusiva não pode ser encarado como um problema, ou como uma barreira intransponível, assim: "mais do que falar em dificuldades é preciso buscar ver as potencialidades. É preciso enxergar o outro pela pessoa que ele é, e não por rótulos" (MELO; SAMPAIO, 2007, p.125).

Uma escola inclusiva não deve ser entendida somente como aquela que recebe alunos com deficiência, visto que, o conceito de inclusão não se resume apenas ao fato da 
SAMPAIO, V. S.; SAMPAIO, A. V. O. ALMEIDA, E. S.

pessoa com deficiência estar matriculada em uma escola regular. Esse aluno tem que ser inserido como um todo e ser parte ativa no processo de ensino e aprendizagem, portanto:

Para uma escola ser inclusiva não basta apenas aceitar os portadores de necessidades especiais, necessita ter um bom projeto pedagógico, que começa pela reflexão e não somente pela infra-estrutura da escola, como construção de rampas, banheiros, entre outros. Também é importante um planejamento quanto à prática pedagógica, proporcionando atividades que envolvam a todos e que os professores entendam que os alunos precisam de liberdade para aprender de acordo com as suas condições (e isto tanto vale para os estudantes com deficiência ou não) (SGARABOTTO \& DURANTI, 2006, p.04)

No processo de ensino e aprendizagem, o docente tem papel fundamental e não deve ser apenas um mero transmissor de conhecimento pronto e acabado, mas sim, um estimulador/mediador do conhecimento e ao mesmo tempo um pesquisador contribuinte para o desenvolvimento da educação. Segundo Melo e Sampaio (2007):

[...] o professor de Geografia em sala de aula tem como função potencializar seus estudantes, utilizando todas as formas diversas de expressões para atingi-los. É preciso entender como estes alunos pensam e se sentem em relação à escola e ao espaço em que vivem" (MELO; SAMPAIO, 2007, p.128).

Uma escola inclusiva deve ser entendida em sentido amplo e não apenas como um caso isolado, visto que é uma realidade que precisa ser debatida. Assim, o professor deve trabalhar em conjunto com toda a comunidade escolar, afinal uma educação inclusiva depende da participação ativa de todos, para que se tenha uma real efetivação desta prática. Nesse context, Melo e Sampaio (2007) ressaltam o professor de Geografia e afirmam:

Garantir uma aula de Geografia acessível à todos com vistas a construir uma escola inclusiva juntamente com outros colegas docentes significa criar condições de participação de todos os membros da comunidade escolar, sejam eles surdos ou gordos, cegos ou baixos, negros ou brancos, deficientes mentais ou muito altos, paraplégicos ou hiperativos, superdotados ou de pés descalços, muito ricos ou com anorexia (MELO; SAMPAIO, 2007, p.128)

O ensino de Geografia tem papel fundamental no enfrentamento destas questões, visto que trabalha diretamente com a produção e transformação do espaço. A Geografia como ciência crítica proporciona uma análise sobre o meio que o indivíduo está inserido, e 
cabe ao profissional, estimular este conhecimento nos alunos, cada um com o seu próprio tempo de aprendizagem.

\section{A educação inclusiva no Brasil}

$\mathrm{O}$ atendimento as pessoas com deficiência no Brasil tem inicio desde a época do império com a criação de diversas instituições que amparavam estas pessoas, e com o passar dos anos surgiram instituições importantes como: o Imperial Instituto dos Meninos Cegos, o Instituto dos Surdos Mudos, o Instituto Pestalozzi, que atendiam pessoas com deficiência mental, e as primeiras Associações de Pais e Amigos dos Excepcionais (APAE). (BRASIL, MEC/SEESP, 2008).

A educação inclusiva no Brasil passa a ter um maior destaque a partir da década de 1980, isso devido aos diversos movimentos de lutas, organizadas por pessoas defensoras dos direitos da pessoa com deficiência. Fernandes (2005) aponta:

No Brasil, a ideia de Educação Inclusiva surge na década de 1980 como fruto da luta das Pessoas com Deficiência e suas entidades, que se organizaram e batalharam por dignidade, revendo sua história e objetivando construir uma nova (FERNANDES, 2005, p.30).

É por meio destas lutas de classes que os dispositivos legais passaram a tratar a temática da educação inclusiva no Brasil. Dentre eles, a Constituição Federal de 1988, a Declaração de Salamanca e a própria Lei de Diretrizes e Bases da Educação Nacional (LDBEN), além dos Parâmetros Curriculares Nacionais (PCNs). Toda essa parte legal reflete uma conquista das pessoas com deficiência no âmbito da educação, pois "tratam do assunto no âmbito da sua legislação, sugerindo uma "Escola para Todos", independentemente se o indivíduo tem ou não uma deficiência" (FERNANDES, 2005, p.30)

A Constituição Federal de 1988, ao tratar da Educação esclarece seu caráter solidário e determina que a educação é um dever do Estado, da família e da sociedade como um todo sempre em busca do pleno desenvolvimento do indivíduo:

A educação, direito de todos e dever do Estado e da família, será promovida e incentivada com a colaboração da sociedade, visando ao pleno desenvolvimento da pessoa, seu preparo para o exercício da cidadania e sua qualificação para o trabalho (BRASIL, C.F, Art.205, 1988)

Geopauta, Vitória da Conquista, ISSN: 2594-5033, V. 4, n.3, 2020, p.(210-226) http://periodicos2.uesb.br/index.php/geo, 
Com relação a Educação inclusiva é possível destacar alguns pontos fundamentais na referida constituição, pois, servem de base geral para os dispositivos legais subsequentes. Em seu artigo 206, ao tratar dos princípios da educação, logo em seu primeiro inciso, ressalta que o ensino terá como base a igualdade de condições para acesso e permanência na escola, o que corrobora diretamente com a ideia de educação para todos. Segundo Crozara e Sampaio:

\begin{abstract}
A escola inclusiva ajuda o indivíduo no princípio da igualdade de oportunidades educativas com várias competências, ajudando-o a compreender a sua realidade e a refletir sobre ela. O sucesso da inclusão de alunos com Necessidades Educativas Especiais na escola regular decorre, portanto, das possibilidades de se conseguir progressos significativos desses alunos na escolaridade, por meio da adequação das práticas pedagógicas à diversidade dos aprendizes (CROZARA \& SAMPAIO, 2008, p.2).
\end{abstract}

Ao tratar dos deveres do Estado sobre a educação, a Carta Magna deixa bem explicita algumas obrigações a respeito da Educação Inclusiva, ao citar em seu artigo 208, inciso III o atendimento educacional especializado aos portadores de deficiência, preferencialmente na rede regular de ensino.

Outro marco importante para a Educação Inclusiva diz respeito ao documento elaborado no ano de 1994, na Conferência Mundial sobre Educação Especial realizado na cidade de Salamanca, na Espanha. A Declaração de Salamanca, como ficou conhecido, nada mais é do que um tratado assinado por diversas nações, inclusive o Brasil, se comprometendo a realizar esforços para a inclusão das pessoas com deficiência nas escolas regulares:

Reconvocando as várias declarações das Nações Unidas que culminaram no documento das Nações Unidas "Regras Padrões sobre Equalização de Oportunidades para Pessoas com Deficiências", o qual demanda que os Estados assegurem que a educação de pessoas com deficiências seja parte integrante do sistema educacional (DECLARAÇÂO DE SALAMANCA, 1994, p.1) 
SAMPAIO, V. S.; SAMPAIO, A. V. O. ALMEIDA, E. S.

A Declaração de Salamanca deu início a diversas leis específicas sobre a Educação Inclusiva, obrigando, de certa forma, as nações signatárias a se comprometerem de fato com o desenvolvimento desta modalidade, como pode ser visto no trecho a seguir:

Nós congregamos todos os governos e demandamos que eles: atribuam a mais alta prioridade política e financeira ao aprimoramento de seus sistemas educacionais no sentido de se tornarem aptos a incluírem todas as crianças, independentemente de suas diferenças ou dificuldades individuais. (DECLARAÇÃO DE SALAMANCA, 1994, p.2)

Além disso, a própria Declaração orienta para a inclusão das pessoas com deficiência na escola, determinando o caráter inclusivo preferencialmente na rede regular de ensino:

O princípio que orienta esta Estrutura é o de que escolas deveriam acomodar todas as crianças independentemente de suas condições físicas, intelectuais, sociais, emocionais, lingüísticas ou outras. Aquelas deveriam incluir crianças deficientes e super-dotadas, crianças de rua e que trabalham, crianças de origem remota ou de população nômade, crianças pertencentes a minorias lingüísticas, étnicas ou culturais, e crianças de outros grupos desavantajados ou marginalizados. Tais condições geram uma variedade de diferentes desafios aos sistemas escolares (DECLARAÇÃO DE SALAMANCA, 1994, p.3 e 4).

Assim, a supracitada declaração se apresenta como o instrumento norteador para o desenvolvimento e implantação da Educação Inclusiva, definindo orientações na parte política, em fatores relativos à escola, recrutamento e treinamento de educadores, os serviços de apoio e até mesmo as áreas prioritárias. Tudo isso demonstra os avanços que a Conferência Mundial sobre Educação Especial promoveu a partir de então.

No Brasil, logo depois da assinatura de comprometimento com a declaração, ocorreu a promulgação da LDBEN, no ano de 1996. A referida lei, além de nortear os sistemas educacionais como um todo, deixou explicito a importância da Educação Inclusiva a ser desenvolvida na rede regular de ensino, pois:

Entende-se por educação especial, para os efeitos desta Lei, a modalidade de educação escolar oferecida preferencialmente na rede regular de ensino, para educandos com deficiência, transtornos globais do desenvolvimento e altas habilidades ou superdotação (BRASIL, LDBEN, art. 58, p.39). 
Além de discriminar sobre o que seria Educação Inclusiva, a LDBEN determina a garantia de alguns direitos que devem ser assegurados pelos sistemas de ensino ao público alvo desta modalidade de ensino:

Os sistemas de ensino assegurarão aos educandos com deficiência, transtornos globais do desenvolvimento e altas habilidades ou superdotação: I - currículos, métodos, técnicas, recursos educativos e organização específicos, para atender às suas necessidades; [...] V - acesso igualitário aos benefícios dos programas sociais suplementares disponíveis para o respectivo nível do ensino regular (BRASIL, LDBEN, art. 59, p.40).

A lei também deixa como situação opcional para o Estado investir quando necessário em instituições privadas sem fins lucrativos com atuação exclusiva em Educação Especial, servindo com apoio técnico a rede regular. Mas, faz uma ressalva de que o Estado deve primeiramente investir em seu próprio sistema de ensino:

[...] O poder público adotará, como alternativa preferencial, a ampliação do atendimento aos educandos com deficiência, transtornos globais do desenvolvimento e altas habilidades ou superdotação na própria rede pública regular de ensino, independentemente do apoio às instituições previstas neste artigo (BRASIL, LDBEN, art. 60, p.41).

O que se pode observar é que de certa forma a legislação está bem contemplada no que diz respeito a Educação Inclusiva, desde a Constituição Federal, a Declaração de Salamanca e a própria LDBEN. Porém, o que precisa ser observado é se na prática tudo que está determinado em lei, de fato está garantido pelo Estado. A Educação Inclusiva perpassa pelo acesso, permanência e aprendizagem para todos os estudantes, sempre respeitando as diferenças, a diversidade e o pluralismo.

\section{Formação docente e a Educação Inclusiva}

Uma das principais dificuldades nos avanços na Educação Especial/Inclusiva diz respeito ao processo de formação docente, que nas universidades, apesar de alguns avanços, pouco preparam para os desafios desta modalidade de ensino. Neste sentido Fernandes (2005) afirma:

A universidade tem se mostrado muito lenta quanto à Educação Inclusiva. Pouco ou quase nada tem feito para que esta proposta de educação ganhe 
SAMPAIO, V. S.; SAMPAIO, A. V. O. ALMEIDA, E. S.

destaque e saia do âmbito do legal. Praticamente não houve mudanças nos currículos dos cursos de licenciatura (com honrosas exceções é claro). Continuamos com currículos atrelados ao conhecimento teórico, com pouca ênfase no conhecimento pedagógico (FERNANDES, 2005, p.36)

Muitas vezes, estas mudanças passam diretamente por uma nova postura não somente dos órgãos normativos, mas também do próprio interesse do meio acadêmico em promover mudanças curriculares significativas para formarem profissionais mais preparados para as dificuldades que venham a existir na prática de ensino na Educação Inclusiva. Fernandes (2005), acrescenta:

Além disso, o próprio Ministério da Educação tem se mostrado omisso com relação ao papel das instituições de ensino superior, não baixando normas para o cumprimento da legislação por parte destas, que continuam se "escondendo" atrás da autonomia universitária para não realizar mudanças estruturais, tão necessárias, principalmente quanto às licenciaturas (FERNANDES, 2005, p.23 e 24).

Além das dificuldades na formação docente, existe ainda a falta de capacitações dos profissionais que estão atuando com alunos com deficiência. Muitos professores não tiveram formação adequada para trabalhar com esse público especificamente, pois:

\begin{abstract}
A formação de professores nos aspectos da Educação Inclusiva permanece como uma necessidade urgente, sendo necessário ajudá-los a vencerem as suas resistências à mudança de modo ao ultrapassarem as limitações e os perigos das concepções baseadas na deficiência. É importante garantir programas de treinamento de professores sobre a inclusão de informações e de práticas de ensino na área da educação inclusiva, tanto em serviço como em sua formação (CROZARA \& SAMPAIO, 2008, p.3).
\end{abstract}

Um dos grandes desafios está também na formação continuada dos professores que trabalham na Educação Inclusiva. E esse é um processo importante, pois, possibilita ao professor repensar sua prática pedagógica de forma constante, buscando aprimorar a aprendizagem dos alunos como um todo, pois:

Sabendo que a educação é um direito de todos, a formação continuada representa um espaço-tempo de constituição e reflexão da ação educativa. É um espaço de potencialização das práticas pedagógicas. Uma oportunidade para (re) pensar as relações de poder existentes no currículo, os mecanismos utilizados para validar os conhecimentos e os pressupostos que fundamentam quem pode ou não aprender na escola (EFFGEN e JESUS, 2012, p.18). 
A formação docente é ampla e exige um grande debate sobre os desafios que o profissional deve enfrentar na educação, além do cumprimento efetivo das legislações vigentes sobre os direitos das pessoas com deficiência em todas as instâncias para que haja de fato uma inclusão social, exigindo assim uma formação crítica do professor, como afirma Cavalcanti:

A formação dos professores de Geografia pode se pautar por essa concepção de profissional critico-reflexivo. Essa formação deve ser aberta a possibilidade de discussão sobre o papel da educação em suas várias dimensões, para a construção da sociedade e para a definição do papel da Geografia na formação geral do cidadão. (CAVALCANTI, 2002, p.112)

Ainda que existam diversas leis que amparam as pessoas com deficiência, pouco se vê a ação efetiva destas leis, fazendo com que haja um processo de isolamento social, entretanto, apesar das barreiras encontradas, é inegável que existam avanços a respeito dos direitos das pessoas com deficiência. Muito disso, se deve as lutas dos movimentos sociais ligados a esta parcela da população. É evidente que sem lutas não existiria conquistas nessa área, pois:

Os ensejos pela educação inclusiva perpassam por ações de cunho político, cultural, social e pedagógico, desencadeadas em defesa do direito de todos os alunos estarem juntos, aprendendo e participando, sem nenhum tipo de discriminação. A educação inclusiva constitui um paradigma educacional fundamentado na concepção de direitos humanos, que conjuga igualdade e diferença como valores indissociáveis e, que avança em relação à ideia de equidade formal ao contextualizar as circunstâncias históricas da produção da exclusão dentro e fora da escola (AMARAL; et. al, 2013, p.2).

Com relação a formação de professores, a LDBEN assegura que os sistemas de ensino deverão garantir aos alunos com deficiência professores especializados para trabalhar com esse público:

Os sistemas de ensino assegurarão aos educandos com deficiência, transtornos globais do desenvolvimento e altas habilidades ou superdotação: [...]III - professores com especialização adequada em nível médio ou superior, para atendimento especializado, bem como professores do ensino regular capacitados para a integração desses educandos nas classes comuns; (BRASIL, LDBEN, art. 59 -III, 2017) 
A questão é saber se de fato estes professores que atuam nas instituições regulares de ensino estão realmente preparados para trabalhar com Educação Inclusiva, e até que ponto esta lei oferece garantias, tanto para os profissionais da educação quanto para os alunos, assim:

\begin{abstract}
Não basta, porém, apenas oferecer aos alunos o acesso à escola. Necessário se faz ministrar um ensino que seja de qualidade para todos, que atenda às reais necessidades dos educandos. Em outras palavras, deve existir abertura para um trabalho pedagógico efetivo com a diferença presente nos educandos, em geral. Para tanto, é imprescindível investir - dentre outros fatores - na formação inicial dos profissionais de educação para atuação com a diversidade do alunado, incluindo nesse contexto os educandos que apresentam deficiência, altas habilidades/ superdotação e transtornos globais do desenvolvimento. (MARTINS, 2012, p.35)
\end{abstract}

Deve-se haver uma preocupação com a formação inicial do professor, bem como, a continuação dessa formação durante a execução do trabalho, afinal o processo de ensino e aprendizagem é constante.

\title{
Ensino de Geografia e educação inclusiva
}

O ensino de Geografia na Educação Inclusiva passa por diversos desafios, desde a formação docente até mesmo a prática do ensino em sala de aula. Os desafios encontrados são diversos e em se tratando do ensino inclusivo, são ainda maiores, pois, cabe ao professor trabalhar diretamente com a formação cidadã dos alunos.

A concepção de uma educação para todos, passa principalmente pela promoção da igualdade e no combate a discriminação e é na formação inicial básica que se apreende estes valores e o educador tem papel essencial neste processo, ademais:

Tudo isso exige do (a) educador (a) preparo para lidar com situações adversas, em que estão presentes indivíduos diferentes com níveis de aprendizado diferentes. O (a) Professor (a) deve estimular o debate entre os(as) alunos(as) sobre as discriminações que marcam as relações sociais, fazendo com que os(as) mesmos(as) percebam que fazem parte de grupos, e que nestes existem as diferenças. A educação deve oportunizar a todos (as) os (as) educandos (as) condições para tornarem-se sujeitos, capazes de refletir sobre seu próprio destino (FERNANDES, 2005, p.32). 
SAMPAIO, V. S.; SAMPAIO, A. V. O. ALMEIDA, E. S.

Na prática do ensino de Geografia, o principal desafio é em relação a metodologia para se trabalhar com alunos com deficiência. Muitas vezes, faltam recursos adequados para um pleno desenvolvimento do trabalho, o que amplia ainda mais as dificuldades do educador. Porém, é necessário que a sala de aula e o plano de trabalho dos conteúdos sejam adequados para os alunos. Amaral et. al. afirmam:

É indispensável que ocorram mudanças e adaptações na sala de aula, em relação aos materiais didáticos como livros, mapas, computadores, jogos; além da postura do professor e sua prática pedagógica, envolvendo a flexibilidade, o respeito, a motivação e a criatividade (AMARAL; et. al, 2013, p.6)

É importante salientar que apesar das constantes preocupações com a metodologia utilizada em sala de aula para o trabalho com alunos com deficiência, este não deve ser o único fator analisado para efetivação de um ensino inclusivo, visto que, outros elementos são extremantes importantes, assim, Caiado et.al, ressalta:

Certo é que os indivíduos com deficiência requerem adaptações individuais. Entretanto, centralizar o foco nas especificidades dos alunos mais do que em adaptações mais significativas, como a formação dos professores, a organização das salas e da escola para atendimento, a relação professor e aluno e entre a família e a escola, dentre outras, podem induzir os pesquisadores na área a acreditarem que mudanças apenas na metodologia já são suficientes para incluir de fato a pessoa com deficiência (CAIADO; et.al, 2015, p. 782)

O ensino de Geografia tem papel fundamental no auxílio da formação de qualquer cidadão, pois desenvolve uma maior compreensão da realidade, ao estudar diretamente com o espaço produzido socialmente, e ainda:

Esta disciplina apresenta papel significativo na aprendizagem, seja por proporcionar o desenvolvimento de habilidades específicas da observação, descrição, análise como aprender a observar, descrever, comparar, estabelecer relações e correlações, tirar conclusões e fazer sínteses do espaço de vivência; seja por possibilitar a apropriação de conteúdos que permitem ler o mundo e o lugar em suas contradições (AMARAL; et. al, 2013, p.8)

Neste sentido, a vivência dos alunos e seus conhecimentos prévios devem ser valorizados e considerados no processo de ensino e aprendizagem, pois é por meio da 
SAMPAIO, V. S.; SAMPAIO, A. V. O. ALMEIDA, E. S.

realidade dos indivíduos que os conteúdos são melhores assimilados principalmente em Geografia. Crozara e Sampaio ressaltam:

É necessário o convívio do professor com o aluno em sala de aula, podendo o mesmo orientar esse aluno conforme suas especificidades, ao desenvolver algum pensamento crítico da realidade por meio da Geografia. A vivência do aluno deve ser valorizada para que ele possa perceber a Geografia como parte do seu cotidiano, trazendo para o interior da sala de aula, com a ajuda do professor, a sua própria experiência do espaço vivido. Para tanto, o estudo da sociedade e da natureza deve ser realizado de forma interativa. (CROZARA \& SAMPAIO, 2008, p.2)

O ensino de Geografia é importante nas discussões e analises da realidade contemporânea. Oliveira (2012) afirma:

Numa abordagem relacional, a Geografia, tendo o espaço como objeto central de estudo e as categorias território, região, paisagem e lugar como seus desdobramentos oferece uma estrutura conceitual para o raciocínio geográfico possibilitando o entendimento da realidade material e de sua representação (OLIVEIRA, 2012, p.3).

Por se tratar de uma disciplina que tem o foco principal nas mudanças sócio espaciais, a Geografia tem suma importância na formação do indivíduo, pois, proporciona um melhor entendimento e uma análise crítica dos lugares, assim:

[...] quando o aluno consegue associar uma disciplina escolar, como a geografia, a sua realidade, esta passa afazer sentido e ter importância para ele. Sem a contextualização adequada dos conteúdos a disciplina em questão continua a ser apenas mais uma matéria escolar sem sentido e sem aplicação. Descaracterizar a disciplina, dissociando-a da vivencia do aluno é simultaneamente descentralizá-la de seu Core e impossibilitar ao educando uma leitura de mundo capaz de situá-lo na realidade que o cerca (ALMEIDA; et. al, 2013, p. 106)

Além da importância do papel do professor enquanto mediador do processo de ensino e aprendizagem, não se pode deixar de lado o foco principal do ensino que é a aprendizagem, ou seja, a construção do conhecimento por parte do aluno, visto que "Ensinar a pensar. Essa é a palavra de ordem que encontramos na maior parte dos livros, projetos, leis, planejamentos, materiais didáticos e mais um sem números de fontes e reflexões em torno da relação ensino e aprendizagem" (SANTOS, 1995, p. 33) 
SAMPAIO, V. S.; SAMPAIO, A. V. O. ALMEIDA, E. S.

Nesse ponto, o conhecimento geográfico deve ser construído na prática cotidiana por alunos e professores. Assim, o ensino não deve pautar apenas na transmissão de conteúdos prontos e acabados, o objetivo deve ser a produção e conhecimento nas práticas cotidianas, pois:

Em suas atividades diárias, alunos e professores constroem Geografia, pois, ao circularem, brincarem, trabalharem pela cidade, pelos bairros, constroem lugares, produzem espaço, delimitam seus territórios; vão formando, assim, espacialidades cotidianas em seu mundo vivido e vão contribuindo para a produção de espaços mais amplos (CAVALCANTI, 2002, p. 33)

A Geografia, embora ainda se fundamente em um modelo tradicional de ensino, que por muitas vezes limita o desenvolvimento do conhecimento geográfico, tem passado por diversas mudanças ao longo da sua sistematização enquanto ciência, e muitos desafios surgiram e ainda surgem ao longo do processo. Oliveira (2012) complementa:

Ao mesmo tempo em que é nítida a importância do conhecimento geográfico e do ensino de Geografia no mundo contemporâneo percebe-se também que ainda são marcantes os problemas enfrentados por essa disciplina, principalmente no tocante à superação do rótulo de matéria decorativa, marca de um ensino de base tradicional caracterizado pelo método descritivo, por procedimentos didáticos baseados na memorização, pelo estudo dicotômico/fragmentado das paisagens naturais e humanizadas, pela produção de livros didáticos puramente conteudísticos, com viés ideológico e alienante (OLIVEIRA, 2012, p.4).

Muitas vezes, à medida que as discussões geográficas avançam nas universidades, nas salas de aulas da educação básica o professor continua limitado ao uso do livro didático, fazendo com que a determinados assuntos fujam a realidade dos alunos e o próprio professor limita o seu conhecimento neste processo.

Este modelo de ensino tradicional vai de encontro ao processo (mesmo que lento) de renovação no entendimento a respeito da educação escolar, em que o objetivo não é exclusivamente o ensino dos conteúdos, mas sim, o desenvolvimento de competências e habilidades, assim:

Essas questões nos colocam a necessidade de repensar o ensino de Geografia, esse deve ser significativo para o aluno, assim como de outros componentes curriculares se fragmentados reforçam a visão tradicional, e ao mesmo tempo uma visão mecanizada (RUFINO, 1995, p.107) 
SAMPAIO, V. S.; SAMPAIO, A. V. O. ALMEIDA, E. S.

Toda mudança no processo de ensino, exige do profissional uma maior desenvoltura no exercício da docência. Essas transformações acarretam, de certa forma, mais trabalho para o professional, pois ele necessitará de mais preparo para desenvolver suas funções de forma satisfatória, isso implica em capacitações constantes, mais estudos, maior compreensão sobre a realidade, visto que os fluxos de informações são cada vez maiores e o professor tem que saber como utiliza-los da melhor maneira possível. Assim:

[...]o processo de formação de professores visa, nessa perspectiva o desenvolvimento de uma competência critico-reflexiva, que lhes permitam meios de pensamento autônomo, que facilite as dinâmicas de autoformação que permita a articulação entre teoria e prática de ensino (CAVALCANTI, 2002, p. 21)

As práticas tradicionais do ensino de Geografia estão diretamente relacionadas a formação docente e, muitas vezes as condições de trabalho impedem o desenvolvimento de aulas mais significativas para os alunos. Almeida; et. al enfatizam:

O que se percebe no cotidiano das aulas de Geografia é que ainda se matem uma abordagem tradicional de ensino, reforçando o caráter mnemônico atribuído a ela, continuando a ser entendida como matéria decorativa, na qual a supervalorização de informações quantitativas e o estudo de conceitos sem a devida aplicação. A mesma linha descritiva é seguida quando, através de questionamentos, é estimulada a participação da turma, pois exigir repostas que prezam pela memorização desmotiva a participação em aula e causa desinteresse em aprender Geografia reforçando o caráter enfadonho atribuído a disciplina (ALMEIDA; et. al, 2013, p. 107).

Se for considerado que essas aulas trazem poucos resultados para os alunos de um modo geral, para os discentes com algum tipo de deficiência o quadro se agrava ainda mais.

O ensino de Geografia na Educação Inclusiva deve proporcionar ao aluno a compreensão e uma melhor análise do meio que o cerca, visto que este indivíduo enfrenta barreiras impostas diariamente em diversas situações cotidianas, desde um simples deslocamento pela cidade, até ao acesso de um ensino de qualidade e voltada para suas especificidades. Na prática do ensino, o professor deve ter o cuidado de adaptar os conteúdos a realidade destes alunos, portanto:

Aprender a reproduzir o conteúdo oficial a ser ensinado é importante para todo e qualquer aluno, mas aprender a pensar sobre os sentidos de orientação e localização espacial, a partir das condições em que se vive, é

Geopauta, Vitória da Conquista, ISSN: 2594-5033, V. 4, n.3, 2020, p.(210-226) http://periodicos2.uesb.br/index.php/geo, 
algo fundamental para a sobrevivência. Tal perspectiva é que deve instigar as escolas e os professores a não apenas ter que ensinar um conteúdo instituído como único, mas criar a partir do que os alunos deficientes trazem de experiência espacial cotidiana, outros conteúdos e informações necessários para ler o mundo a partir do lugar em que se encontram (VIEIRA; FERRAZ, 2015, p. 06).

Outro ponto a ser tratado diz respeito às pesquisas relacionadas ao ensino de Geografia voltadas para os alunos com deficiência, pois, quanto mais diversificados forem os estudos realizados na área, maior será a compreensão e o aprimoramento do ensino desta disciplina para este público. "Em relação aos temas, o mais frequente é o do Ensino de Geografia para pessoas com deficiência visual (baixa visão e/ou cegueira). Entretanto, os dados apontam para a diversificação dos temas nas diferentes deficiências a partir de 2011" (CAIADO; et. al, 2015). Percebe-se também estudos relacionados a formação docente e os diversos desafios enfrentados em sala de aula. Sobre isso Caiado, et. al (2015) ressalta:

Sobre a formação dos professores, o foco tem sido nos desafios da prática docente em ensinar a pessoa com deficiência na sala comum sem ter tido formação, inicial e continuada, na área. São escassas as propostas de formação de professores de geografia que contemplem as pessoas com deficiência para além das adaptações metodológicas de ensino (CAIADO; et.al, 2015, p. 783)

Neste contexto, a necessidade de maiores estudos e pesquisas sobre a prática de ensino de Geografia na Educação Inclusiva é uma realidade para possibilitar aos profissionais o desenvolvimento de um trabalho de qualidade e estimulador para os alunos com deficiência, promovendo de fato a inclusão destes indivíduos no ambiente escolar e na sociedade de modo geral.

\section{Considerações Finais}

A inclusão do aluno com deficiência na rede regular de ensino foi uma conquista histórica para estes indivíduos. A obrigatoriedade de recursos e metodologias, discriminados em leis como a LDBEN de 1996 deveria atender os alunos com deficiência e suas especificidades. A questão é debater se as escolas consideradas inclusivas realmente promovem um processo efetivo de inclusão, ou se esses alunos estão apenas inseridos em classes regulares. 
Nesse contexto, o ensino de Geografia, assim como das demais disciplinas escolares, trazem alguns desafios, e um fator que deve ser considerado para a superação das barreiras existentes é a formação inicial e continuada do professor, bem como o aprimoramento de estudos na área, para o desenvolvimento de metodologias que de fato proporcionem um aprendizado significativo para estes alunos. Porém, é preciso se atentar que o processo de inclusão não se estabelece apenas na prática em sala de aula, mas sim nas diversas relações desenvolvidas cotidianamente.

\section{Referências}

ALMEIDA, J. P.; et. al. Uma Reflexão acerca do Ensino de Geografia e da Inclusão de Alunos Surdos Em Classes Regulares. Revista Brasileira de Educação em Geografia. Campinas, v. 3, n. 5, p. 98-118, Jan/Jun. [2013]. Disponível em:

http://www.revistaedugeo.com.br/ojs/index.php/revistaedugeo/issue/view/9. Acesso em: 17 Out. 2019.

AMARAL, C. N.; et. al. Geografia e inclusão: Práticas Educativas Para Alunos Desatentos. In: REENCONTRO DE SABERES TERRITORIALES LATINOAMERICANOS. 14. egal. 2013. Peru. Anais Eletrônicos [...] Encuentro de Geógrafos de América Latina, [2013]. Disponível em: http://www.egal2013.pe/wp-content/uploads/2013/07/Tra_Vin\%C3\%ADcius-Ramos-da-SilvaMiriam-Rezende-Bueno-Claudilene-do.pdf . Acesso em 15 Mar. 2018.

BRASIL. [Constituição (1988)]. Constituição da República Federativa do Brasil de 1988. Brasília, DF: Senado Federal, [2016]. Disponível em: https://www2.senado.leg.br/bdsf/bitstream/handle/id/518231/CF88_Livro_EC91_2016.pdf. Acesso em: 8 Mai. 2018.

BRASIL. Lei $\mathbf{n}^{0}$ 9.394, de 20 de dezembro de 1996. Lei de Diretrizes e Bases da Educação Nacional. Brasília, DF: Senado Federal, [2017]. Disponível em: https://www2.senado.leg.br/bdsf/bitstream/handle/id/529732/lei_de_diretrizes_e_bases_1ed.pdf. Acesso em: 9 Mai. 2018.

BRASIL. Ministério da Educação. Secretaria de Educação Especial/MEC. Política Nacional De Educação Especial Na Perspectiva da Educação Inclusiva. Inclusão: Revista da Educação Especial. Brasília, V.4, n.1, p 7-17, Jan/Jun. [2008]. Disponível em: http://portal.mec.gov.br/seesp/arquivos/pdf/revinclusao5.pdf. Acesso em: 15 Out. 2019.

CAIADO, K. R. M.; et. al. Produção Do Conhecimento Sobre o Ensino de Geografia para Pessoas com Deficiência. Revista Ibero-Americana de Estudos em Educação. Universidade Estadual Paulista, Faculdade de Ciências e Letras. Araraquara, v. 10, n. esp, p. 773-786, jul. [2015]. Disponível em: https://periodicos.fclar.unesp.br/iberoamericana/issue/viewIssue/528/108. Acesso em: 10 Nov. 2019.

CAVALCANTI, L. S. Geografia e Práticas de Ensino. Alternativa, Goiânia, 2002.

CROZARA, T. F.; SAMPAIO, A. Á. M. Construção de material didático tátil e o ensino de geografia na perspectiva da inclusão. Anais Eletrônicos do VIII Encontro Interno/XII Seminário de Iniciação Científica, Uberlândia. [2008]. Disponível em: 
https://ss14799.websiteseguro.com/swge5/seg/cd2008/PDF/IC2008-0305.PDF. Acesso em: 15 Fev. 2018.

DECLARAÇÃo DE SALAMANCA. Sobre Princípios, Políticas e Práticas na Área das

Necessidades Educativas Especiais. Salamanca-Espanha. [1994]. Disponível em:

http://portal.mec.gov.br/seesp/arquivos/pdf/salamanca.pdf. Acesso em: 12 Jun. 2018

EFFGEN, A. P. S; JESUS, D. M. Formação docente e práticas pedagógicas: conexões, possibilidades e tensões. In: O professor e a Educação Inclusiva: formação, prática e lugares. EDUFBA, Salvador, 2012. Disponível em: https://repositorio.ufba.br/ri/handle/ri/12005. Acesso em 08 Out. 2019.

FERNANDES, A.; "Utopia” da Educação Inclusiva e a Formação dos (as) Professores(as) de Geografia - Vencendo Paradigmas. Monografia (Bacharel em Geografia) - Instituto de Geografia, Universidade Federal de Uberlândia, Uberlândia, 2005. Disponível em:

http://www.geografiaememoria.ig.ufu.br/downloads/Antonio_Fagundes_2005.pdf. Acesso em: 5 set. 2018.

FERRAZ, C. B. O; VIEIRA, J. M. O Desafio do Ensino de Geografia para Deficientes Visuais.

Revista Geografia em Atos - GeoAtos. XVI Semana de Geografia "AGB Presidente Prudente 40 anos: As reflexões e perspectivas da Geografia". Faculdade de Ciências e Tecnologia da Universidade Estadual Paulista "Júlio de Mesquita Filho" - UNESP. Presidente Prudente, v. 2, n. 2. [2015]. Disponível em: http://revista.fct.unesp.br/index.php/geografiaematos/article/view/3864/3029. Acesso em: 5 nov. 2019.

MARTINS, L. A. R. Reflexões sobre a formação de professores com vistas à educação inclusiva. In: O professor e a Educação Inclusiva: formação, prática e lugares. EDUFBA, Salvador, 2012. Disponível em: https://repositorio.ufba.br/ri/handle/ri/12005. Acesso em: 08 Out. 2019.

MELO. A. Á.; SAMPAIO, A. C. F. Educação inclusiva e formação de professores de geografia: primeiras notas. Caminhos de Geografia - Revista Online, Uberlândia, v. 8, n. 24, p. 124-130, DEZ/2007. Disponível em: http://www.seer.ufu.br/index.php/caminhosdegeografia/article/view/15622. Acesso em: 10 Jul. 2018.

MENDES, E. G. A radicalização do debate sobre inclusão escolar no Brasil. Revista Brasileira de Educação, v. 11 n. 33, p. 387-589, set./dez. 2006. Disponível em: http://www.scielo.br/pdf/rbedu/v11n33/a02v1133.pdf. acesso em: 15 set. 2018

RUFINO, S. M. V. C. A construção do conceito de espaço e o ensino de Geografia. AGB. Dossiê: Geografia e ensino. In: Caderno Prudentino de Geografia. Nº17, Presidente Prudente, 1995.

SANTOS, D. Conteúdo e Objetivo pedagógico do Ensino de Geografia. AGB. Dossiê: Geografia e ensino. In: Caderno Prudentino de Geografia. Nº 17, Presidente Prudente, 1995.

SGARABOTTO, A. L.; DURANTI, R. R. T. Aprendizagem em geografia por adolescentes com deficiência visual em uma escola estadual regular1. Caxias do Sul, 2006. Disponível em: http://www.educadores.diaadia.pr.gov.br/arquivos/File/2010/artigos_teses/2010/ Geografia/art_geo_visual.pdf. Acesso em: 15 set. 2018

OLIVEIRA, A. C. C. A. Competências didático pedagógicas para o ensino de geografia e os desafios á prática docente. Anais Eletrônicos do VI Colóquio Internacional "Educação e Contemporaneidade". São Cristovão, Set, 2012. Disponível em: http://www.educonufs .com.br/cdvicoloquio/eixo_05/PDF/10.pdf. Acesso em: 12 Mar. 2018 